\title{
Selection and breeding programs for disease resistance in sugarcane
}

\author{
John martin Jerome Jeyakumar * and Muqing Zhang \\ State Key Lab for Conservation and Utilization of Subtropical Agro-Biological Resources, Guangxi University, Nanning, \\ Guangxi, 530005, China.
}

Publication history: Received on 26 February 2020; revised on 11 March 2020; accepted on 12 March 2020

Article DOI: https://doi.org/10.30574/gscarr.2020.2.3.0016

\begin{abstract}
The genetic complexity of sugarcane, attaining novel genotypes for it is comparatively due to mechanisms of vegetative propagation. Breeding for higher yield and quality traits requires basic information on the extent of genetic variation in a population and its response to selection. Improving the genetic potential of qualitative and quantitative traits is the most important goal in the breeding program for sugarcane. The different breeding approaches aimed at developing types with new characteristics, it seems that better awareness of the biological network will effectively lead cultural management, thus increasing the capacity of present cultures through genomic selection in addition to enhancing new ones. This review summarizes the identification and functional characterization of the breeding programs and current understanding of the immunity against various diseases in sugarcane.
\end{abstract}

Keywords: Breeding Techniques; Nobilization; Germplasm; GxE interaction; Sugarcane

\section{Introduction}

Sugarcane is the cash crop with significant demand in the country [1]. In addition to sugar production, it also produced worldwide by-products such as Bagasse and Molasses [2]. In most disease-resistant plant breeding programs, success in developing resistant crop cultivars is achieved in a relatively short time. Plant breeding, crossing and pollination selection of sugarcane cultivars with favorable characteristics and generating inter-specific sugarcane hybrids with a combination of desirable characteristics [3]. It is thought that some of the cultivated varieties make a great contribution to the genome of these species in different proportions [4]. Disease control resistance is the easiest, cost-effective and less health hazardous precautionary and control measure in opposition to the various diseases of sugarcane like pokkah boeng, Smut, etc. Resistance durability depends on pathogen variation, mechanisms, and inheritance of resistance and farm management practices [5]. As revealed from morphological, physiological, and marker data [6], variation in natural Fusarium populations tends to be large. The sugarcane breeding programs are currently benefiting from methods developed to estimate genetic parameters. It is important to note that each breeding program adopts specific techniques in line with its needs and purposes [7]. The genetic complexity of sugarcane, obtaining new genotypes for it is relatively easy due to mechanisms of vegetative propagation. All these varieties were developed through mutations that were induced. Genetic variability and heritability are useful parameters that can help breeding during various crop improvement stages [8,9]. Therefore, a clear understanding of genetic parameters is important to develop a breeding strategy. Here, we review the current knowledge of the biological functions and how they exert their roles at the breeding programs.

\footnotetext{
* Corresponding author: John martin Jerome Jeyakumar
} 


\section{Selection programmes of sugarcane}

One of the oldest methods of breeding, and is the premise of all crop improvement practiced by historical farmers. Selection is completely based on plant phenotype. The effectiveness of choice usually depends on the extent to which the plant phenotypes replicate their genotype [10]. Selection indices are useful in understanding the extent of improvement by a combination of characters so as to improve the selection efficiency through indirect selection for bringing genetic improvement of yield. The potential advantage of selection indices is that several traits are improved simultaneously. The decisive objective of plant breeding is to generate dynamic cultivars for enhanced traits [11]. Early generation selection involves identifying sugarcane families comprising a greater proportion of high cane yielding seedlings followed by selecting individual seedlings with the potential to produce high cane yield from these elite families [12]. Genotype-by-environment (GE) interaction effects and the competition among closely spaced seedlings as well as clones planted in small plots [13] are known to influence the precision of individual seedling selection during early generation selection [14]. GE interaction effects are important for traits controlled by quantitative genes such as cane yield [15]. [16] Proposed the distinct steps involved in breeding. First, large quantities of selections are made from the genetically variable unique population. Second, rows of progeny are grown from the selections of the plants for observational purposes. Finally, the chosen and inbred strains are compared with varieties in its yielding performance and other elements of agronomic importance. Selecting advanced genotypes in the early generation might be highly ineffective for numerous crops particularly those cloned propagated. To steer clear of the screening problems, molecular genetic markers could be hired to pick out the genotypes having desired characteristics in breeding program aiming at development of varieties with improved resistance.

\section{Genetic studies on sugarcane}

One of the most vital landmarks in plant breeding records have been the successful utilization of Saccharum spontaneum in sugarcane development. In no other crop, wild species have been so successfully applied to fulfill human desires. This species wild. S.spontaneum indicates high levels of resistance to biotic and abiotic stresses. The ingenious idea of using this wild species to improve sugarcane. As a female crossed S.officinarum into $S$. spontaneum as a male with the idea of infusing biotic and abiotic stress resistance into the cultivated sugarcane [17]. An advanced multiplication method utilizing tissue culture procedures, micropropagation involves small parts of a plant such as shoot tips and nodes grown in an artificial medium in a germ-free environment. Micropropagation has increased the multiplication rate of HYV (high yield variety) planting material exponentially, helping planters improve farm yields. The cutting-edge technique has reduced the lag time of new varieties because it enables breeders to generate numerous plantlets in a short span of time. Restriction fragment length polymorphism (RFLP) markers are generally phenotype-neutral, free of environmental influence, have a high level of allelic variation, and are apparently free of epistatic and pleiotropic effects. Furthermore, they are detectable in all tissues at any stage of plant development. The development of RFLP markers is technically complex, time-consuming, and expensive, and involves safety considerations due to the use of radioactive probes. These aspects, coupled with the requirement for large amounts of DNA and cloned and characterized probes, has raised questions as to whether RFLP technology is compatible with large-scale crop improvement programs, despite its usefulness in generating genetic markers.

\section{Features and consequences of nobilization}

[18] cytological studies showed that asymmetric transmission of the chromosome is characterized by nobilization. An intersection between S. officinarum $(2 \mathrm{n}=80)$ as parent female, and $S$. spontaneum $(2 \mathrm{n}=40-128)$ as a parent male. In general, S.officinarum transmits two sets of haploid chromosomes while S.spontaneum passes on one. This process of $2 \mathrm{n}+\mathrm{n}$ transmission is repeated once again when the hybrid is backcrossed to S.officinarum as the female [19]. $2 \mathrm{n}$ gametes may or may not function in further backcrosses depending on the specific S.officinarum clones that may be used [20]. It is critical to note that while uneven chromosome transmission is the norm in S.officinarum $\mathrm{x}$ S.spontaneum hybrids as opposed to the exception, from these interspecific crosses rare times of $n+n$ progeny were pronounced, regularly involving S.spontaneum [21]. During selection, therefore, variety improvement in sugarcane hybrids is likely to be due to retention of S.spontaneum chromosomes with favorable net effects, while those with unfavorable effects are rejected. 


\section{Conventional breeding}

Traditional breeding of sugarcane is impeded through a slender gene pool and complicated genome derived from small group of progenitor clones [22]. Other elements such as infertility, long breeding cycles, and cold intolerance additionally restrict breeding advancements of some sugarcane strains. During the last three to 4 decades, traditional sugar cane breeding has notably elevated yield, ratooning ability and resistance to disease [23]. Conventional breeding is often based on empirical yield choices [24], which is a way out of optimum, because yield is a quantitative feature and is characterized by low heritability and high environmental genotype interactions $(G \times E)$. Crop physiology and genomics have generated new insights into stress tolerance and plant improvement tools to breeders [25]. Natural choice has desired variation and survival mechanisms; breeding hobby has directed choice toward increasing the financial yield of cultivated species [26]. By deciding on yield and secondary characteristics, genetic improvement for drought resistance has been addressed using a conventional approach [27]. [28] anticipated the advances in molecular techniques have contributed in particular to the use and enhancement of germplasm along with innovative procedures for plant breeding under stress conditions. A range of molecular resources have been developed and identified for improving sugarcane. [22] Most of the traits that breeding programmes seek to improve resistance.

\section{Utilization of germplasm}

The different breeding techniques aimed at developing types with new characteristics, it appears that better knowhow of the biological network can successfully lead to cultural management, thus increasing the potential of present cultures, in addition to improving recent ones, by means of "assisted genomic selection." One of the main components of plant breeding is the identification of germplasms containing genes that could improve the performance of current cultivars [29]. Wild species have a degree of excessive genetic variation. Since cultivated types are generally derived from only a few accessions of ancestral or wild species and had been subject to repetitive choice, the variety of variations includes the acquisition of germplasm through collections and repatriations from genebanks or from different sources, the characterization and evaluation of germplasm, and the selection of suitable genotypes by mass and/or normally pure line. Germplasm thus has great potential value for improvement of crop varieties.

\section{G×E interaction}

Genotype $\times$ environment interaction is a significant factor for genetic improvement in identifying excessive yield and stable cultivars suitable for regional sugar industry components [30]. Environmentally interactive genotypes are common for most economically important quantitative traits. The selection of genotypes to maximize yield across environments is complicated due to the complexity of responses to the genotype. In-plant breeding programs, desirable genotypes are selected after evaluation under different environments. Most of the sugarcane component is highly influenced by environmental factors such as germination, tillering, and stalk elongation [31].The crop is harvested when sucrose accumulation within the stalks reaches a peak and the time to maturity also varies depending on genotype and growing conditions.

\section{Conclusion}

An understanding of cane yield and interrelationships among other module traits with economic yield is also important to adopt an appropriate breeding strategy. Cane yield is a highly complex quantitative character influenced by several component characters and hence direct selection may not be reliable. Studies of G x E sugarcane interactions are limited, having focused on the strategy of breeding and selection networks in the future when attempted. Moreover, the use of a post-release cultivar assessment program as a tool to implement various strategies may be a rational option to the diversity of such trial networks. Various resources and tackle are persistently been made available for sugarcane in order to understand its genome, genetics, physiology, molecular biology, new markers associated with traits of agronomical significance. Breeding programs should take advantage of these tools and integrate in their selection strategy to generate advanced new cultivars that respond to current and future production needs and anticipate the wide spectrum of civilization. 


\section{Compliance with ethical standards}

\section{Acknowledgments}

The authors acknowledge the State Key Laboratory for Conservation and Utilization of Subtropical Agro-bioresources and Guangxi special funding for availing valuable literature resources for this work.

\section{Disclosure of conflict of interest}

The authors declare no conflict of interest.

\section{References}

[1] Solomon S. (2016). Sugarcane Production and Development of Sugar Industry in India. Sugar Tech, 18, 588-602.

[2] Akbar A and Ali I. (2017).Value-Added By-Products from Sugar Processing Industries. In Food Processing ByProducts and their Utilization, A.K. Anal (Ed.).

[3] Butterfield MK, D'Hont A and Berding N. (2001). The sugarcane genome: A synthesis of current understanding, and lessons for breeding and biotechnology. Proc. S. Afr. Sug. Technol. Ass., 75, 1-5.

[4] Matsuoka S. et al. (1999). Melhoramento de cana-de- açúcar.In: BORÉM, A. (Ed.). Melhoramento de espéciescultivadas. Viçosa: Imprensa Universitária, 205-251.

[5] Parlevhet JE. (1993). what is durable resistance, a general outline. In: Th. Jacobs, and J. E. Parlevliet (eds), Durabihty of Disease Resistance, 23-40.

[6] SchUhng AG. (1996).Charaetedzation and differentiation of the cereal pathogens Fusarium culmorum and F. graminearum by PCR-based moleeular markers. PhD Thesis, Univ. Hohenheim, Germany.

[7] Gazaffi R, Margarido GRA, Pastina MM, et al. (2014). A model for quantitative trait loci mapping, linkage phase, and segregation pattern estimation for a full-sib progeny. Tree Genetics \& Genomes 10, 791-801.

[8] Anshuman S, Bhatnagar PK, Khan AQ and Shrotria PK. (2002). Variability and heritability for cane yield, its components and quality characters in sugarcane (Saccharum spp complex). Indian. Sug. J., 53(4), 717- 719.

[9] Ahmed AO and Obeid A. (2012).Investigation on variability, broad sensed heritability and genetic advance in sugarcane (Saccharum spp). International Journal of Agricultural Science, 2 (9), 839-844.

[10] Mohd Shamshad and Achla Sharma.(2018).The Usage of Genomic Selection Strategy in Plant Breeding, Next Generation Plant Breeding, Yelda Özden Çiftçi, IntechOpen.

[11] Moose SP and Mumm RH. (2008). Molecular plant breeding as the foundation for 21st century crop improvement. Plant physiology, 147(3), 969-977.

[12] Zhou MM, Kimbeng CA, Andru S, Tew TL, Pontif MJ and Gravois KA. (2013). Evaluating Sugarcane Families for Yield Potential and Repeatability Using Random Coefficient Models. Crop Sci., 53, 2352-2362.

[13] Tovey DA, Glasziou KT, Farquhar RH and Bull TA. (1973). Variability in radiation received by small plots of sugarcane due to differences in canopy heights. Crop Sci., 13, 240-242.

[14] Jackson P and McRae TA. (2001). Selection of sugarcane clones in small plots: effects of plot size and selection criteria. Crop Sci., 41, 315-322.

[15] Skinner JC, Hogarth DM and Wu KK. (1987).Chapter 11 - Selection Methods, Criteria, and Indices. In Developments in Crop Science, Heinz, D.J., Ed. Elsevier, 11, 409-453.

[16] Kimbeng C, Rattey AR and Hetherington M. (2002). Interpretation and implications of genotype by environment interactions in advanced stage sugarcane selection trials in Central Queensland. Aust. J. Agric. Res., $53,1035-1045$.

[17] Breseghello Flavio and Coelho Alexandre. (2013).Traditional and Modern Plant Breeding Methods with Examples in Rice (Oryza sativa L.). Journal of agricultural and food chemistry, 61. 
[18] Ali A, Khan M, Sharif R, Mujtaba M and Gao SJ. (2019). Sugarcane Omics: An Update on the Current Status of Research and Crop Improvement. Plants, 8.

[19] Bremer G. (1961). Problems in breeding and cytology of sugar cane. Euphytica, 10, 59-78.

[20] Yu F, Wang P, Li X, et al. (2018). Characterization of chromosome composition of sugarcane in nobilization by using genomic in situ hybridization. Mol Cytogenet , 11, 35.

[21] Wu J, Huang Y, Lin Y, Fu C, Liu S, Deng Z, Li Q, Huang Z, Chen R and Zhang M. (2014).Unexpected inheritance pattern of Erianthus arundinaceus chromosomes in the intergeneric progeny between Saccharum spp. and Erianthus arundinaceus. PloS one, 9(10), e110390.

[22] Sreenivasan TV, Ahloowalia BS and Heinz DJ.(1987). Sugarcane improvement through breeding. Amsterdam: Elsevier, 211-254.

[23] Jackson PA. (2005). Breeding for improved sugar content in sugarcane. Field Crops Research, 92, 277-290.

[24] Lakshmanan P, Geijskes RJ, Wang L, Elliott A, Grof CPL, Berding N and Smith GR. (2006). Development and hormonal regulation of direct shoot organogenesis and somatic embryogenesis in sugarcane (Saccharum spp. Interspecific hybrids) leaf culture. Plant Cell Reports, 25, 1007-1015.

[25] Atlin GN and Lafitte HR (2002) Marker-assisted breeding versus direct selection for drought tolerance in rice. In: Saxena NP, O'Toole JC (eds) Proceedings of international workshop on field screening for drought tolerance in Rice, India.

[26] Tuberosa R and Salvi S. (2006). Genomic based approaches to improve drought tolerance in crops. Trends Plant Sci, 11, 1260-1285.

[27] Cattivelli L, Rizza F, Badeck FW, Mazzucotelli E, Mastrangelo A, Francia E, Marè C, Tondelli A and Stanca, A. (2008). Drought tolerance improvement in crop plants: An integrated view from breeding to genomics. Field Crops Research, 1-14.

[28] Farooq M, Hussain M, Wahid A and Siddique K. (2012). Drought Stress in Plants: An Overview.

[29] Govindaraj M, Vetriventhan M and MS. (2015). Importance of Genetic Diversity Assessment in Crop Plants and Its Recent Advances: An Overview of Its Analytical Perspectives. Genetics Research International.

[30] Maureira I and Osborn T. (2004). Molecular Markers in Genetics and Breeding: Improvement of Alfalfa (Medicago sativa L.). In: Lörz H., Wenzel G. (eds) Molecular Marker Systems in Plant Breeding and Crop Improvement. Biotechnology in Agriculture and Forestry, 55. Springer, Berlin, Heidelberg

[31] Tiawari DK, Pandey P, Singh RK, Singh SP and Singh SB. (2011). Genotype x Environment Interaction and Stability Analysis in Elite Clones of Sugarcane (Saccharum officinarum L.). International Journal of Plant Breeding and Genetics, 5, 93-98.

[32] Smith D, Inman-Bamber N and Thorburn P. (2005). Growth and function of the sugarcane root system. Field Crops Res. 92, 169-183.

\section{How to cite this article}

Jerome Jeyakumar JM and Muqing Z. (2020). Selection and breeding programs for disease resistance in sugarcane. GSC Advanced Research and Reviews, 2(3), 44-48. 